\title{
Efeito da adubação fosfatada na produção de sementes de soja ${ }^{1}$
}

\author{
Rosidelma da Silva Felício Marin², Carlos André Bahry³, Maicon Nardino ${ }^{4}$, Paulo Dejalma Zimmer \\ http://dx.doi.org/10.1590/0034-737X201562030006
}

\begin{abstract}
RESUMO
O fósforo pode contribuir com o aumento de qualidade das sementes produzidas e incrementar a produtividade de grãos. O objetivo deste trabalho foi avaliar o efeito da adubação fosfatada sobre a qualidade, a composição química e a produtividade das sementes de soja e, a produtividade de grãos em lavoura estabelecida partir dessas sementes. Foram realizados dois ensaios. No Ensaio 1 avaliaram-se os seguintes tratamentos: T1 - controle, semeadura sem $\mathrm{P}_{2} \mathrm{O}_{5}$; T2 - 50\% a menos que a dose de $\mathrm{P}_{2} \mathrm{O}_{5}$ recomendada com base na análise do solo; T3 - 100\% da dose de $\mathrm{P}_{2} \mathrm{O}_{5}$ recomendada; T4 - 50\% a mais que a dose de $\mathrm{P}_{2} \mathrm{O}_{5}$ recomendada; e, T5 - 100\% a mais que dose de $\mathrm{P}_{2} \mathrm{O}_{5}$ recomendada. Após a colheita foram determinados o número de sementes e de legumes por planta, a produtividade, a germinação, a viabilidade e o vigor por meio do teste tetrazólio, a composição química e a massa de mil sementes. No Ensaio 2, as sementes colhidas no Ensaio 1 foram semeadas e avaliou-se o número de legumes e o de grãos por planta e a produtividade. O delineamento experimental utilizado nos dois ensaios foi em blocos ao acaso, com cinco repetições. A adubação fosfatada proporciona maior vigor das sementes de soja, além de contribuir para o aumento de fósforo, ferro e zinco nas sementes produzidas. Sementes com maiores concentrações de fósforo em sua constituição contribuem para o aumento de produtividade da soja.
\end{abstract}

Palavras-chave: vigor, análise química das sementes, concentração de P.

\section{ABSTRACT}

\section{Effect of phosphate fertilization in production of soybean seeds}

Phosphorus can contribute to increase seed quality and grain yield. The aim of this study was to evaluate the effect of phosphorus fertilization on quality, chemical composition and yield of soybean seeds and yield of crops established from these seeds. Assay 1 evaluated the following treatments: $\mathrm{T} 1$ - control, sowing without $\mathrm{P}_{2} \mathrm{O}_{5}$; T2: $50 \%$ less than the recommended $\mathrm{P}_{2} \mathrm{O}_{5}$ rate based on the soil analysis; T3: $100 \%$ of the recommended $\mathrm{P}_{2} \mathrm{O}_{5}$ rate; T4: 50\% more than the recommended $\mathrm{P}_{2} \mathrm{O}_{5}$ rate; and T5: $100 \%$ more than the recommended $\mathrm{P}_{2} \mathrm{O}_{5}$ rate. After harvest, the number of seeds and pods per plant, yield, germination, viability and vigor by tetrazolium test, chemical composition and thousand-seed weight were determined. Assay 2 was conducted with the seeds harvested in Assay 1 to evaluate the number of pods per plant, number of seeds per plant and yield. The experiment was arranged in randomized blocks with five replicates. The phosphorus fertilization provided greater vigor in soybean seeds, besides contributing to increased phosphorus, iron and zinc in seeds produced. Seeds with higher phosphorus concentration contribute to the increase in soybean yield.

Key words: vigor, chemical seeds analysis, P concentration.

\footnotetext{
Submetido em 15/04/2013 e aprovado em 01/04/2015.

${ }^{1}$ Este trabalho é parte da Dissertação de Mestrado do primeiro autor.

Fazenda 5M, Rondonópolis, Mato Grosso, Brasil. delma.f@terra.com.br

${ }^{3}$ Universidade Tecnológica Federal do Paraná, Departamento de Ciências Agrárias, Pato Branco, Paraná, Brasil. carlosbahry@utfpr.edu.br

${ }^{4}$ Universidade Federal de Pelotas, Departamento de Fitotecnia, Pelotas, Rio Grande do Sul, Brasil. nardinomn@gmail.com

${ }^{5}$ Universidade Federal de Pelotas, Departamento de Fitotecnia, Pelotas, Rio Grande do Sul, Brasil. dejalma@msn.com

*Autor para correspondência: carlosbahry@utfpr.edu.br
} 


\section{INTRODUÇÃO}

A cultura da soja ocupa uma posição de destaque no agronegócio brasileiro. Isso se deve, inicialmente, às extensas áreas cultivadas a partir das décadas de 1970 e 1980, principalmente pela exploração do cerrado brasileiro. No entanto, a crescente demanda por uma agricultura mais eficiente e sustentável fez com que os agricultores encontrassem no aumento de produtividade, a única forma de se manter na atividade e, também, de contribuir para o aumento da produção de grãos.

Nesse sentido, ganha destaque a utilização de sementes de soja de alta qualidade, pois é por meio delas que as novas tecnologias introduzidas pelo melhoramento genético vegetal são levadas aos agricultores (Carraro \& Peske, 2005), contribuindo substancialmente para o aumento de produtividade. No entanto, deve-se considerar, também, que as práticas de manejo adotadas pelos produtores de sementes são fundamentais para a obtenção de sementes com maior qualidade. Uma das práticas mais importantes para isso é a adequada nutrição das plantas.

$\mathrm{O}$ fornecimento de macro e micronutrientes, em especial para a soja cultivada no cerrado brasileiro, constitui-se uma ferramenta indispensável para se alcançar altas produtividades. Isso se justifica, pois os solos do cerrado são ácidos, na sua maioria, e com baixa disponibilidade de nutrientes, em especial o fósforo. Além disso, este nutriente está sujeito à retenção por oxihidróxidos de ferro e alumínio, minerais normalmente presentes em maiores quantidades nos solos tropicais; o que acaba restringindo a adequada absorção de fósforo pelo sistema radicular das plantas (Malavolta, 2006). Assim, a prática de adubação é indispensável para obtenção de alta produtividade, podendo, também, ser uma forma de elevar o teor do nutriente nas sementes.

Alguns autores sugerem que o fósforo pode interferir positivamente no atributo da qualidade fisiológica da semente (Cadore, 2011) e que, além disso, essa melhoria refletir-se-ia em incrementos na produtividade de grãos da geração seguinte (Trigo et al., 1997; Peske et al., 2009). A disponibilidade de fósforo junto à semente pode facilitar o desenvolvimento inicial das plântulas de soja (Corrêa et al., 2004), proporcionando um estande mais vigoroso e, com isso, mais competitivo, garantindo, assim, uma lavoura mais uniforme e, consequentemente, com maior potencial produtivo.

Os resultados obtidos pela pesquisa são promissores, indicando haver efeito benéfico do fósforo na qualidade de sementes de soja e na produtividade da cultura. Porém, nos trabalhos realizados por Trigo et al. (1997), Corrêa et al. (2004) e Peske et al. (2009) houve benefícios do fósforo à planta de soja em condição de vaso, o que pode não se repetir em condição de campo.
Diante da possibilidade de se obterem ganhos significativos para a cultura da soja em função da adubação fosfatada, numa condição de lavoura comercial, neste trabalho, objetivou-se avaliar os efeitos de diferentes doses de fósforo aplicadas na semeadura da soja sobre a qualidade fisiológica, a composição química e a produtividade das sementes colhidas e, a partir dessas sementes, estabelecer uma nova lavoura para avaliar a produtividade de grãos.

\section{MATERIAL E MÉTODOS}

\section{Ensaio 1- Produção de sementes com doses crescentes de fósforo}

O ensaio foi conduzido na Fazenda 5M, localizada no município de Itiquira, Mato Grosso (Latitude: -

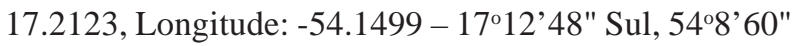
Oeste; 511 metros de altitude; clima tropical com estação seca: Aw, de acordo com Köppen-Geiger), em um Latossolo Vermelho-Amarelo (LVAm). A área foi cultivada com algodão por cinco anos consecutivos. Na safra anterior ao ensaio, foi ocupada com soja seguida de milho safrinha.

O cultivar de soja utilizado foi o CD 242 RR, de ciclo semiprecoce, hábito de crescimento determinado e grupo de maturação 7.9, indicado, pelo obtentor, para solos de alta fertilidade.

A coleta de solo para análise química e física (Tabela 1) foi realizada por amostragens na camada de 0 a 0,20 $\mathrm{m}$ de profundidade. $\mathrm{O}$ solo foi preparado por meio de duas gradagens pesadas com discos de 28 polegadas e a incorporação do calcário foi realizada 90 dias antes da semeadura, por grade niveladora, numa profundidade de $0,20 \mathrm{~m}$, na dose de uma tonelada por hectare de calcário magnesiano.

A dessecação da cobertura vegetal presente foi realizada com o herbicida glifosato, aplicado na área experimental 20 dias antes da semeadura, na dose de 1,0 L.ha ${ }^{-1}$.

$\mathrm{Na}$ área experimental, primeiramente, foram definidas as linhas de semeadura com os discos da semeadora e, posteriormente, as parcelas foram delimitadas com estacas. Usando-se uma enxada de lâmina estreita, e seguindo-se a linha de semeadura, foi realizado um sulco de aproximadamente $10 \mathrm{~cm}$ de profundidade para distribuir manualmente o fertilizante.

As parcelas foram constituídas de seis linhas de três metros de comprimento, com $0,45 \mathrm{~m}$ de espaçamento entre linhas, totalizando $8,1 \mathrm{~m}^{2}$ por parcela. As linhas externas de cada parcela, uma de cada lado, e $1 \mathrm{~m}$ do comprimento das linhas $(0,5 \mathrm{~m}$ de cada lado) foram utilizadas como bordadura da parcela, totalizando uma área útil colhida de $3,6 \mathrm{~m}^{2}$. 
No primeiro ano de cultivo (Ensaio 1) foi avaliada a aplicação de fósforo, na forma de Super Fosfato Triplo (TSP), na linha de semeadura, distribuído manualmente cinco centímetros abaixo das sementes. Foram utilizados os seguintes tratamentos: T1 - controle, sem adubação fosfatada na semeadura da soja; $\mathrm{T} 2$ - dose de $\mathrm{P}_{2} \mathrm{O}_{5}$ $50 \%$ menor que a recomendada pela interpretação da análise de solo (Tabela 1); T3 - 100\% do $\mathrm{P}_{2} \mathrm{O}_{5}$ recomendado pela interpretação da análise de solo; T4 - 50\% a mais de $\mathrm{P}_{2} \mathrm{O}_{5}$ que o recomendado pela interpretação da análise de solo; e, T5 - 100\% a mais de $\mathrm{P}_{2} \mathrm{O}_{5}$ que o recomendado pela interpretação da análise de solo. Essas percentagens equivaleram a $0 \mathrm{~kg} \cdot \mathrm{ha}^{-1}$ (T1); 27,17 kg.ha-1 (T2); 54,34 kg.ha-1 (T3); 81,51 kg.ha-1 (T4); e, 108,68 $\mathrm{kg} \cdot \mathrm{ha}^{-1}$ (T5) de $\mathrm{P}_{2} \mathrm{O}_{5}$.

A semeadura foi realizada na primeira quinzena de novembro de 2009. As sementes foram tratadas com fungicida Vithavax-Thiran, inseticida Standak na dose de $200 \mathrm{~mL}$, Gaucho (100 g) e inoculante líquido (50 mL) para cada $100 \mathrm{~kg}$ de sementes. Quando as plantas encontravam-se com cinco folhas foi realizada aplicação de $100 \mathrm{~kg} \cdot \mathrm{ha}^{-1}$ de $\mathrm{KCl}$ em cobertura. A colheita foi realizada na segunda quinzena de fevereiro de 2010 .

\section{Componentes de rendimento e produtividade}

As variáveis respostas analisadas foram as seguintes:

Número de legumes por planta: somatório dos legumes de todas as plantas coletadas na área útil de cada parcela, dividindo-se o total pelo número de plantas.

Número de sementes por planta: somatório das sementes de todas as plantas coletadas na área útil de cada parcela, dividindo-se o total pelo número de plantas.

As sementes foram secadas até umidade de $12 \%$. Procedeu-se então à análise da produtividade, por aferição da massa das sementes colhidas em cada parcela, para cada tratamento, transformando-se o resultado para $\mathrm{kg} \cdot \mathrm{ha}^{-1}$. Para tanto, realizou-se a determinação do teor de água das sementes com o Determinador de Umidade Universal - EH - modelo III. Logo após, as sementes foram armazenadas em sacos de papelão multifoliado em local arejado, com temperatura controlada entre 20 e $22{ }^{\circ} \mathrm{C}$ para minimizar a redução da qualidade fisiológica, até o momento da semeadura da próxima safra.

\section{Qualidade fisiológica das sementes}

Imediatamente após o acondicionamento das sementes, uma amostra representativa foi coletada e submetida a testes realizados no laboratório da Associação dos Produtores de Sementes de Mato Grosso (APROSMAT), a saber:

Massa de mil sementes: realizada por pesagem de oito repetições de 100 sementes por repetição de cada tratamento, fazendo-se a correção para a massa de mil sementes, em kg (Brasil, 2009).

Porcentagem de germinação: realizada com oito repetições de 50 sementes por tratamento, semeadas em papel substrato, umedecido na proporção de 2,5 vezes o seu peso seco. As sementes foram colocadas à temperatura de $25^{\circ} \mathrm{C}$, de acordo com as Regras para Análises de Sementes (Brasil, 2009). A primeira contagem foi realizada aos cinco dias e a contagem final realizada aos oito dias após a semeadura.

Viabilidade e Vigor pelo Teste de Tetrazólio: preparado com solução estoque de tetrazólio a 1,0\%. A solução de trabalho foi preparada na concentração de $0,075 \%$. A avaliação foi realizada com 100 sementes de cada tratamento, divididas em duas subamostras de 50 sementes. Com o auxílio de lupa com aumento de seis vezes e com iluminação fluorescente, as sementes foram avaliadas individualmente e classificadas quanto à viabilidade e vigor, de acordo com França-Neto et al. (1998).

\section{Composição química das sementes}

Também se analisou a composição química das sementes provenientes de cada tratamento com fósforo. Para tanto, coletou-se amostra representativa de cada repetição de campo, unindo-as em uma amostra composta. No laboratório de análises agronômicas TecSolo, a amostra composta foi dividida em quatro amostras de trabalho para se proceder as análises, totalizando quatro repetições para cada tratamento.

\section{Ensaio 2 - Cultivo com sementes obtidas em doses crescentes de fósforo}

No local da instalação do Ensaio 2, na Fazenda 5M, 90 dias antes da semeadura, foi utilizado gesso agrícola na dose de uma tonelada por hectare, incorporado até a profundidade de 0,2 metros.

Tabela 1. Características químicas e físicas do solo em que o experimento foi realizado

\begin{tabular}{|c|c|c|c|c|c|c|c|c|c|c|}
\hline \multirow{2}{*}{$\begin{array}{l}\text { M.O. } \\
(\mathrm{g} / \mathrm{kg})\end{array}$} & \multirow[t]{2}{*}{ pH } & \multirow{2}{*}{$\begin{array}{c}\text { CTC } \\
\left(\mathrm{cmol}_{\mathrm{c}} / \mathrm{dm}^{3}\right)\end{array}$} & \multirow{2}{*}{$\begin{array}{c}\mathrm{V} \\
(\%)\end{array}$} & $\mathbf{P}$ & $\mathbf{K}$ & $\mathbf{S}$ & $\mathbf{C a}$ & Mg & Al & $\mathbf{H}+\mathbf{A l}$ \\
\hline & & & & \multicolumn{3}{|c|}{$\left(\mathrm{mg} / \mathrm{dm}^{3}\right)$} & \multicolumn{4}{|c|}{$\left(\mathrm{cmol}_{\mathrm{c}} / \mathrm{dm}^{3}\right)$} \\
\hline 19 & 5,0 & 5,3 & 41,4 & 11,5 & 42 & 21 & 1,9 & 0,6 & 0,1 & 3,7 \\
\hline $\mathbf{Z n}$ & & $\mathrm{Cu}$ & & $\mathrm{Fe}$ & B & Argila & & & & Solo \\
\hline \multicolumn{5}{|c|}{$\left(\mathrm{mg} / \mathrm{dm}^{3}\right)$} & & \multicolumn{4}{|c|}{$(\mathrm{g} / \mathrm{kg})$} & \\
\hline 2,0 & & 0,7 & & 32 & 0,13 & 300 & & & & LVAm \\
\hline
\end{tabular}


A semeadura foi realizada na segunda quinzena de outubro de 2010, com semeadora Jumil Pneumatic. A adubação foi de $250 \mathrm{~kg} \cdot \mathrm{ha}^{-1}$ da formulação NPK 00-1818, distribuída a lanço, em pré-emergência, e de 80 kg.ha${ }^{1}$ de $\mathrm{KCl}$, em pós-emergência, quando as plantas encontravam-se com cinco folhas. A colheita foi realizada na primeira quinzena de março.

\section{Componentes de rendimento e produtividade}

Os componentes de rendimento avaliados foram o número de legumes por planta e número de grãos por planta, por meio da avaliação de 12 plantas, coletadas aleatoriamente em cada repetição, de cada tratamento e, a produtividade, após o teor de umidade ter sido ajustado para $12 \%$, avaliada na área total de cada parcela, transformando-se os resultados para kg.ha- ${ }^{-1} \mathrm{O}$ ciclo do cultivar apresentou incremento de 15 dias, por causa da precipitação pluviométrica, acima da média, que atingiu a região no período de enchimento de grãos. Dados de precipitação dos dois anos agrícolas em que se conduziu o ensaio encontram-se na Figura 1.

$\mathrm{O}$ delineamento experimental aplicado para os Ensaios 1 e 2 foi em blocos ao acaso, com cinco repetições. Os dados foram submetidos à análise de variância e regressão, a 5\% de probabilidade de erro. $\mathrm{O}$ efeito das doses de fósforo na produtividade de sementes (Ensaio 1), assim como na produtividade de grãos (Ensaio 2), foram avaliados por análise de regressão linear com nível de significância de 5\% de probabilidade, sendo as equações ajustadas pelo maior grau significativo do polinômio.

\section{RESULTADOS E DISCUSSÃO}

\section{Componentes de rendimento e produtividade}

O componente de rendimento da soja número de legumes por planta, no Ensaio 1 (safra 2009/2010), não foi sensível às diferentes doses de fósforo aplicadas na linha de semeadura, não havendo significância (Figura 2A). Esses resultados discordam dos obtidos por Zucareli et al. (2006) na cultura do feijão, cv IAC Carioca. Segundo os autores, a dose de $150 \mathrm{~kg} \cdot \mathrm{ha}^{-1}$ de fósforo $\left(\mathrm{P}_{2} \mathrm{O}_{5}\right)$ também na forma de super fosfato triplo, contribuiu para o incremento dessa variável, assim como para o número de sementes por planta, não havendo reflexo, no entanto, na produtividade final do feijoeiro. Nas doses menores testadas, não se observou diferença em relação ao controle. No presente estudo, a dose máxima aplicada foi de 108,68 kg.ha-1 de fósforo $\left(\mathrm{P}_{2} \mathrm{O}_{5}\right)$, não diferindo, também, da dose zero.

Semelhantemente ao observado no Ensaio 1, o número de legumes por planta no Ensaio 2 também não foi influenciado por diferentes concentrações de fósforo na composição das sementes (Figura 2B), evidenciando-se, no caso deste estudo, que a variação na concentração de fósforo não alterou este componente de rendimento da soja. Trigo et al. (1997) observaram que a concentração de fósforo crescente nas sementes de soja $(0,58 \%$ a $1,10 \%)$ contribuiu com incremento em torno de $20 \%$ no número de legumes por planta, em solo com adubação fosfatada, e de $15 \%$, porém, não menos importante, em solo sem adubação fosfatada.

Possivelmente, o motivo de se ter verificado resultados distintos para o número de legumes por planta no presente estudo, em comparação ao desenvolvido por Trigo et al. (1997), esteja no fato de que o último foi realizado em vaso, possibilitando maior sensibilidade de resposta da planta às diferentes concentrações de $\mathrm{P}$ no solo e na semente, já que a exploração do sistema radicular foi menor, em função da disponibilidade de espaço para crescimento horizontal e vertical. No presente estudo, por ser conduzido em campo, a alteração deste componente devido às concentrações de $\mathrm{P}$ pode ter sido minimizada pela maior quantidade de plantas por área e sua consequente distribuição entre plantas na li-

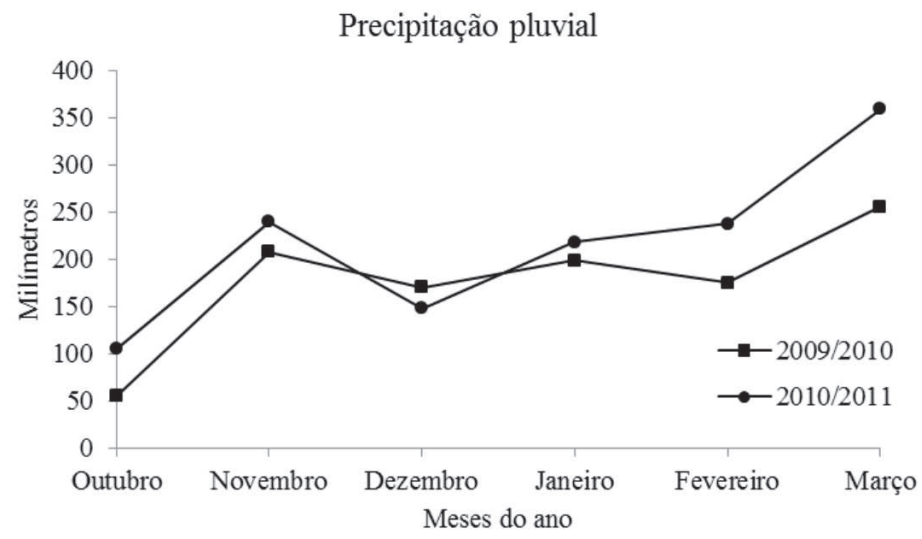

Figura 1. Dados de precipitação pluvial coletados no local do experimento, nas safras de 2009/2010 e 2010/2011, entre os meses de outubro e março. 
nha de semeadura; além da maior possibilidade de exploração de solo por parte do sistema radicular.

Em relação ao número de sementes por planta, também não se observou efeito significativo para essa variável no Ensaio 1 (Figura 2C). Peske et al. (2009) obtiveram resultado positivo na maior dose de fósforo aplicada diretamente na semente por meio do recobrimento com fitina (fonte provedora de fósforo e outros cátions), em relação a esse componente de rendimento, tanto em solo com alta disponibilidade de fósforo quanto em solo com baixa disponibilidade do nutriente, de acordo com análise de solo, em experimento realizado em vaso, atribuindo o incremento de produtividade, obtido em seu trabalho, ao aumento do número de sementes por planta.

No Ensaio 2, foi possível verificar ajuste linear para essa variável, explicando em torno de $45 \%$ do resultado (Figura 2D). Esse ajuste linear foi diretamente proporcional ao fornecimento de fósforo às plantas do Ensaio 1 , mostrando o potencial das sementes de primeira geração, geradas a partir de plantas nutridas com doses crescentes de P na linha de semeadura, para originarem plantas passíveis de maximizar a expressão dos componentes de rendimento, neste caso, o número de grãos por planta, podendo contribuir com a produtividade da lavoura de soja. Contudo, deve-se levar em consideração que outros fatores não mensurados influenciaram nesse resultado, devido ao coeficiente de determinação ser menor que 50\%. Trigo et al. (1997) verificaram efeito positivo e proporcional para a concentração de fósforo na semente e o aumento do número de sementes produzidas por planta na primeira geração. Esse aumento representou $20 \%$ a mais de sementes por planta, independentemente da adubação, ou não, com fósforo. Contudo, devidas comparações merecem ressalvas, visto que o presente trabalho foi desenvolvido em condição de campo e o realizado por Trigo et al. (1997), em vasos.

De acordo com Cadore (2011), o recobrimento de sementes de trigo com fitina e fosfato natural contribuiu para o aumento do número de sementes por planta, apresentando tendência linear positiva.

Outro componente de rendimento avaliado, porém, apenas nas sementes produzidas no Ensaio 1, foi a massa de mil sementes (Figura 3A). Apesar do baixo valor do coeficiente de determinação, observou-se, de maneira geral, que o fornecimento de fósforo contribuiu para o aumento da massa das sementes, havendo maior massa no tratamento que recebeu a maior dose de fósforo na semeadura $\left(108,68 \mathrm{~kg} \cdot \mathrm{ha}^{-1}\right.$ de $\left.\mathrm{P}_{2} \mathrm{O}_{5}\right)$, mostrando o efeito positivo da adubação fosfatada neste componente. Contudo, apesar do efeito positivo verificado, a equação não explica todo o resultado em função do $\mathrm{P}$, visto que o $\mathrm{R}^{2}$ foi de $32 \%$, merecendo critério na sua generalização.

Ao avaliarem os efeitos da adubação fosfatada e potássica na soja, aplicada na linha de semeadura e em diferentes distâncias em relação às sementes, Moterle et al. (2009) observaram que o componente que mais
A

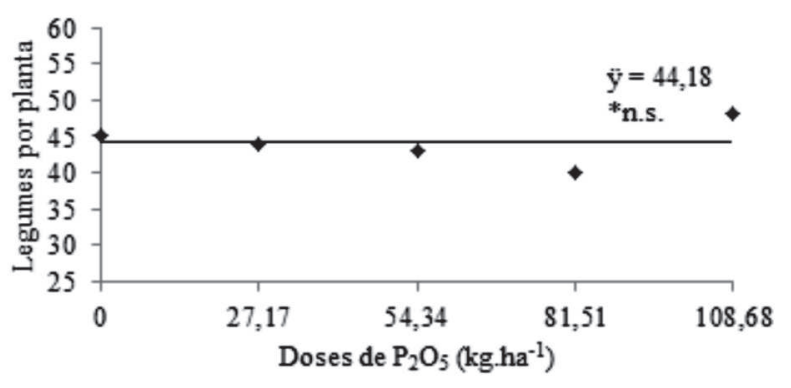

B

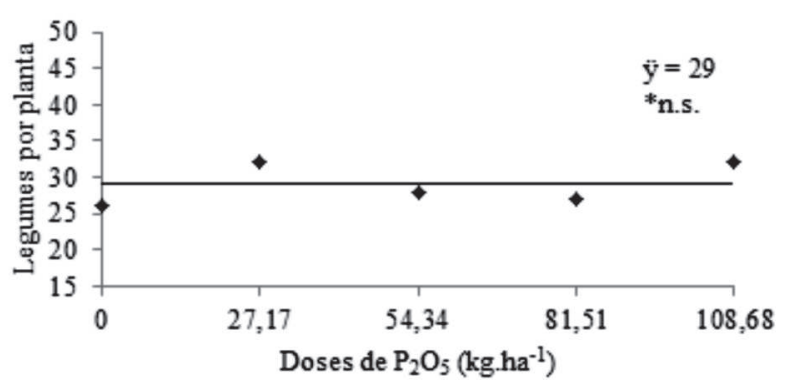

$\mathrm{C}$

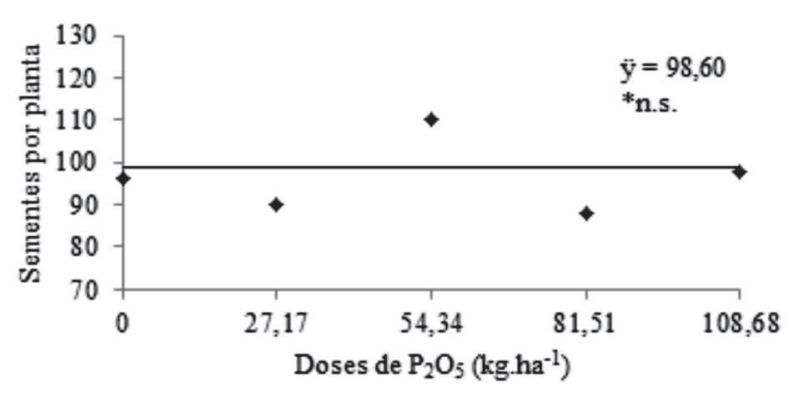

D

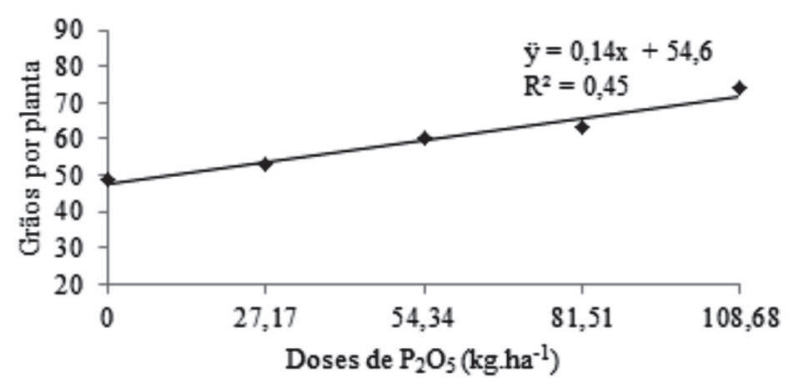

Figura 2. Número de legumes por planta (A - Produção das sementes); B - Cultivo subsequente); número de sementes por planta (C - Produção das sementes) e número de grãos por planta (D - Cultivo subsequente) em função de doses de fósforo utilizadas na produção das sementes de soja. *n.s.: não significativo. 
contribuiu para o incremento de produtividade da cultura foi a massa das sementes. Alteração nessa variável não foi verificada em trabalhos desenvolvidos por Trigo et al. (1997) e Peske et al. (2009), também com sementes de soja; Zucareli et al. (2011), com sementes de feijão e Cadore (2011), com sementes de trigo.

Em relação à produtividade da soja do Ensaio 1, não se observou influência das diferentes doses de fósforo testadas no incremento dessa variável, não havendo ajuste de equação (Figura 3B). Por meio de experimento realizado em vaso com solução nutritiva Rosolem \& Tavares (2006) verificaram que houve diferença significativa para tratamentos com e sem fósforo, em várias características estudadas, dentre elas a produtividade da cultura da soja, sendo esta prejudicada quando houve quadro de deficiência de $\mathrm{P}$ na fase reprodutiva. Zucareli et al. (2011), testando diferentes doses de fósforo na semeadura do feijão, cultivar Carioca Precoce, obtiveram re- sultados significativos e positivos, à medida que aumentaram as doses de fósforo na linha, até $150 \mathrm{~kg} \cdot \mathrm{ha}^{-1}$ de P.

No Ensaio 2, observou-se ajuste linear e positivo para produtividade de grãos (Figura 3C), nos tratamentos provenientes das sementes geradas sob maiores doses de fósforo na linha de semeadura, aplicadas no Ensaio 1. A produtividade obtida no controle foi de $2.935,20 \mathrm{~kg}$.ha- ${ }^{-1}$ de grãos (Ensaio 2). Já no tratamento proveniente de sementes geradas sob adubação superior de $\mathrm{P}$ na linha de semeadura (T5) do Ensaio 1, a produtividade de grãos (Ensaio 2) obtida, em função do enriquecimento de $\mathrm{P}$ proporcionado às sementes, foi de 4.430,90 kg.ha-1, evidenciando a importância de se ter sementes com maiores concentrações de $\mathrm{P}$ na sua composição química para potencializar o arranque inicial das plantas, garantindo assim um estabelecimento inicial mais vigoroso e plantas mais aptas a competir por água, luz e nutrientes, contribuindo para o ganho de produtividade.

A

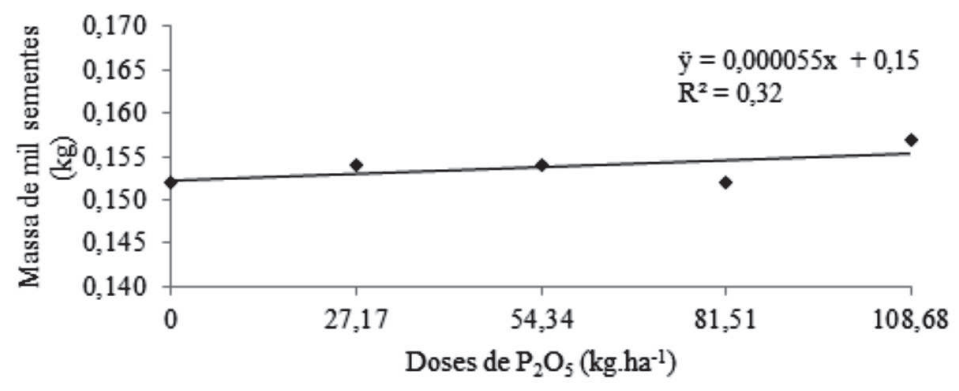

B

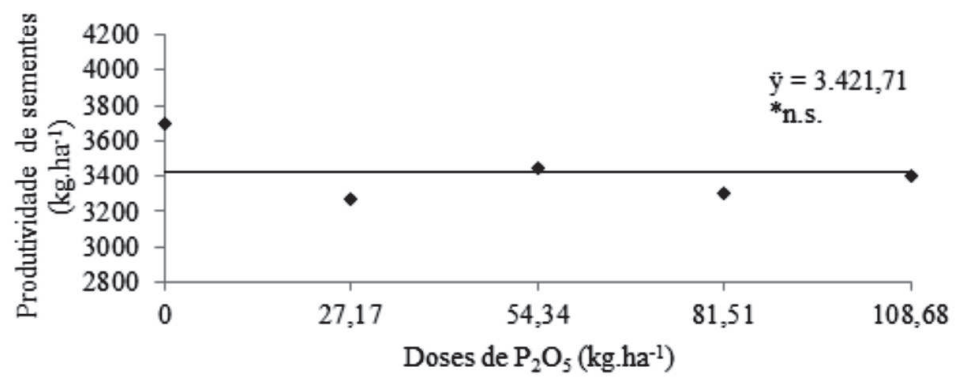

C

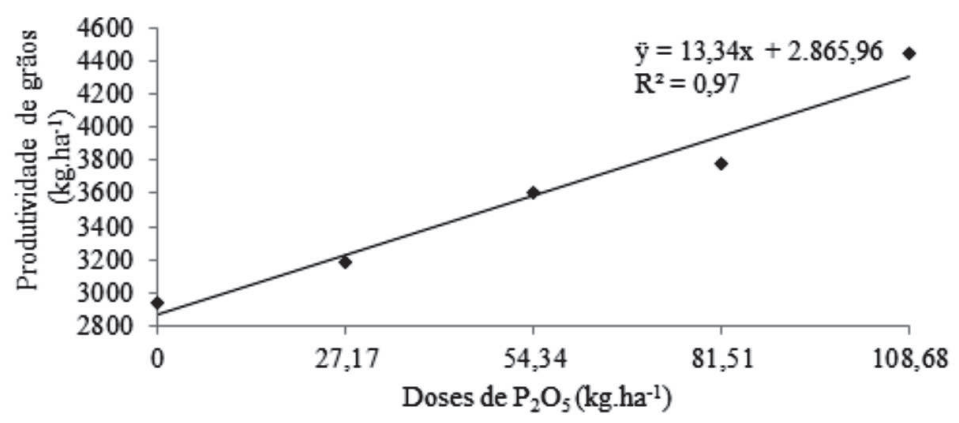

Figura 3. Massa de mil sementes (A), produtividade de sementes (B) e produtividade de grãos (C) em função das doses de fósforo utilizadas na produção das sementes. *n.s.: não significativo.

Rev. Ceres, Viçosa, v. 62, n.3, p. 265-274, mai-jun, 2015 
Uma hipótese para explicar o efeito da concentração de fósforo na semente e o incremento de produtividade na soja foi desenvolvida por Trigo et al. (1997). Segundo os autores, "concentrações mais elevadas de $\mathrm{P}$ nas sementes proporcionariam maior disponibilidade de energia para as atividades metabólicas da semente, o que levaria ao maior crescimento inicial das plântulas e ao desenvolvimento maior e mais rápido do sistema radicular, resultando no aumento da absorção de nutrientes e, consequentemente, na capacidade produtiva da planta".

Estudando o aumento da concentração de fósforo na semente de soja, Trigo et al. (1997) constataram aumento de produtividade de $37 \%$ quando sementes com alta concentração de $\mathrm{P}$ eram cultivadas em solo com níveis adequados de fósforo, e aumento de $20 \%$ na produtividade quando essas mesmas sementes eram cultivadas em solos pobres em fósforo. Apesar da diferença de $17 \%$, mesmo em solos pobres no nutriente, sementes que apresentaram maiores concentrações de $\mathrm{P}$ conduziram a uma lavoura mais produtiva.

O presente estudo difere dos principais trabalhos realizados no Brasil para avaliar o efeito do fósforo na qualidade de sementes e na produtividade da cultura da soja (Trigo et al., 1997; Peske et al., 2009), pois foi realizado em lavoura e insere-se na realidade do produtor de sementes, que explora extensas áreas com a cultura da soja e, nesse sentido, trabalhos científicos nessa modalidade podem contribuir com resultados mais aplicados, gerando informações técnicas passíveis de adoção no campo, podendo os produtores utilizarem o enriquecimento de sementes com fósforo, por meio da adubação fosfatada, para diferenciar seu produto no mercado de sementes.

\section{Qualidade fisiológica das sementes}

As distintas doses de fósforo não alteraram a germinação e a viabilidade das sementes de soja (Figura 4A e $4 \mathrm{~B}$, respectivamente) não sendo, essas variáveis, sensíveis às concentrações diferenciais de fósforo na linha de semeadura (Ensaio 1). Observou-se, também, equivalência entre o teste padrão de germinação e a viabilidade avaliada pelo teste de tetrazólio, devido à semelhança nos resultados.

O vigor das sementes, também avaliado pelo teste de tetrazólio, foi sensível aos diferentes tratamentos de fósforo. Houve ajuste quadrático, no entanto, pouca amplitude de variação foi observada entre o controle até o tratamento 3, que recebeu fósforo de acordo com a recomendação da análise de solo. Para as sementes provenientes dos tratamentos que receberam doses de fósforo acima da recomendação, foi observado efeito positivo para o vigor das sementes, tendo as sementes do tratamento T5, que recebeu a maior dose na semeadura, apresentado maior vigor que às sementes submetidas aos demais tratamentos do Ensaio 1 (Figura 4C); evidenciando o papel do fósforo na semeadura como um importante promotor da qualidade das sementes produzidas, mas não o único, obviamente. Esse resultado vem ao encontro do observado por Guerra et al. (2006), os quais, ao avaliarem o efeito da aplicação de diferentes doses de fósforo na soja sobre a qualidade fisiológica das sementes colhidas, constataram melhora da qualidade das sementes, por meio do teste de tetrazólio, da germinação e da emergência a campo.

\section{Composição química das sementes}

A análise química dos macro e micronutrientes foi realizada nas sementes colhidas no Ensaio 1. Observouse um padrão distinto entre os nutrientes. $\mathrm{O}$ teor de nitrogênio não foi alterado em função dos diferentes tratamentos de fósforo, não havendo ajuste de equação (Figura 5A). Esse resultado vem ao encontro do observado por Silva \& Vahl (2002) e Salum et al. (2008), em sementes de feijão. Possivelmente, isso se deve ao fato de que o $\mathrm{N}$ é o nutriente que se encontra em maior quantidade nas sementes de soja, com valores bem superiores aos de P. Assim, mesmo havendo incremento deste último nas sementes, este não é suficientemente grande para ocasionar alteração nos teores de N.

$\mathrm{O}$ teor de fósforo na semente apresentou um comportamento variável para os diferentes tratamentos avaliados neste estudo. Observou-se semelhança na concentração de fósforo na semente entre os tratamentos T1 e T2 (controle e 50\% a menos da recomendação, respectivamente) (Figura 5B). A partir do tratamento 3, o teor de $\mathrm{P}$ na semente apresentou relação positiva com o aumento da dose de P na linha de semeadura. As sementes do tratamento que recebeu a maior dose de fósforo $\left(108,68 \mathrm{~kg} \cdot \mathrm{ha}^{-1}\right.$ de $\left.\mathrm{P}_{2} \mathrm{O}_{5}\right)$ apresentaram maior concentração desse nutriente em relação aos demais; indicando que o fósforo, além de contribuir para o crescimento e desenvolvimento adequados da planta, apresenta maior acúmulo nas sementes à medida que sua dose na linha de semeadura é aumentada. Corrêa et al. (2004), testando diferentes doses de $\mathrm{P}$ por hectare, obtiveram resultado positivo quanto à concentração de fósforo nas sementes à medida que se aumentou a concentração do nutriente no solo, com melhor resultado na maior dose aplicada, $150 \mathrm{~kg} \cdot \mathrm{ha}^{-1}$ de $\mathrm{P}$, vindo ao encontro do observado neste estudo.

As concentrações de potássio e magnésio nas sementes não foram influenciadas em função dos tratamentos de fósforo na linha de semeadura.

No caso do enxofre (S), verificou-se pequena redução da concentração deste, nas sementes, à medida que 
A

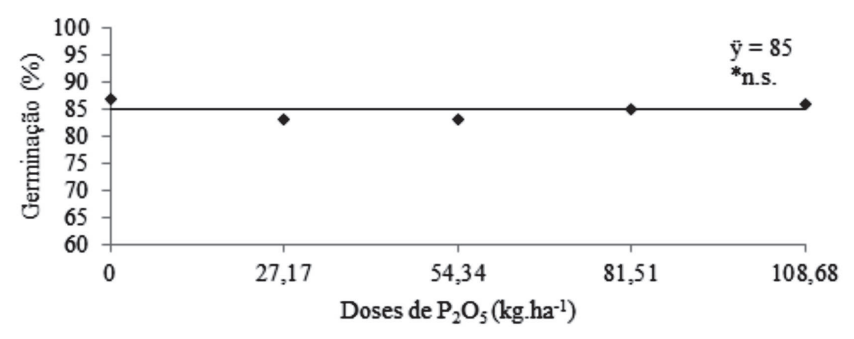

B

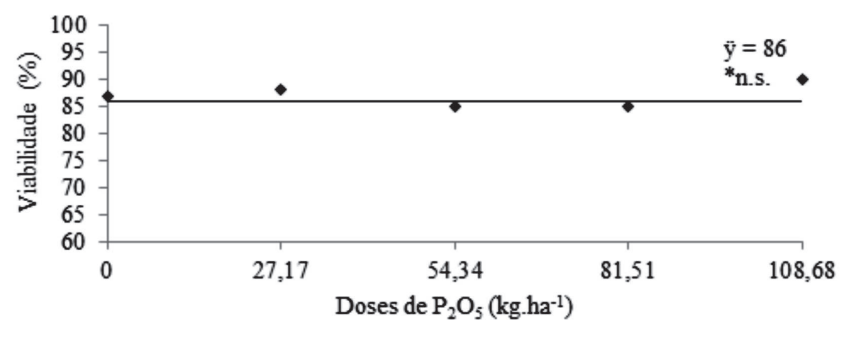

$\mathrm{C}$

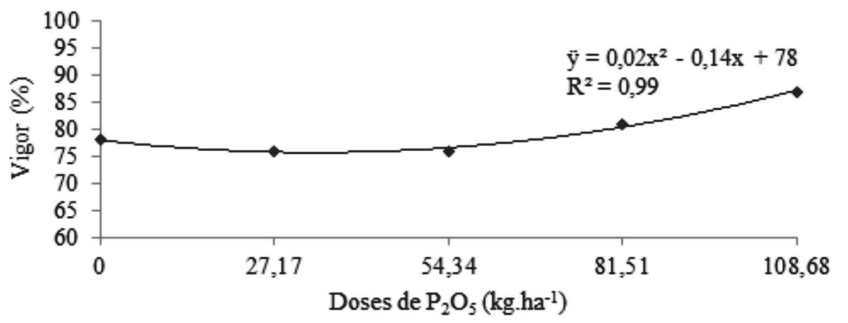

Figura 4. Germinação (A), viabilidade (B) e vigor (C) de sementes de soja colhidas de plantas cultivadas sob diferentes doses de fósforo na linha de semeadura. *n.s.: não significativo.

se aumentou, nestas, o teor de P (Figura 5E). De acordo com Malavolta (1980), o S é um nutriente demandado pelas culturas em quantidades muito próximas às do $\mathrm{P}, \mathrm{o}$ que pode ocasionar competição entre ambos os nutrientes. Soma-se a isto, o fato de os dois nutrientes serem absorvidos pelas plantas na forma de ânions. Esse resultado não corrobora com o verificado por Salum et al. (2008). Os autores não observaram alteração do teor de $\mathrm{S}$ em função de diferentes doses de $\mathrm{P}$ no solo e nas sementes, com exceção das doses 0 e 90 kg.ha ${ }^{-1}$ de $\mathrm{P}$ no solo; logo, resultado pouco conclusivo em feijão, pois em doses maiores a essa, o resultado foi igual ao controle.

Da mesma forma, o cálcio apresentou um comportamento pouco variável entre os tratamentos de $\mathrm{P}$, com leve queda na sua concentração no tratamento que recebeu a maior quantidade de fósforo na linha de semeadura, em relação à do controle, porém, sem diferir muito (Figura 5F). Resultado semelhante a este foi observado por Salum et al. (2008), os quais constataram, em cultivares de feijão Carioca Precoce e IAC-Carioca Tybatã que, na maior concentração de $\mathrm{P}$ na semente, o teor de Ca foi menor.
Em relação aos micronutrientes, destaque para o zinco e o manganês. À medida que se aumentou a concentração de fósforo na linha de semeadura (e na semente), houve um aumento da concentração de zinco nas sementes geradas dos tratamentos 3, 4 e 5 (Figura 6A). Na literatura disponível, resultados referentes à interação entre $\mathrm{P}$ e Zn mostram-se contraditórios. Alguns pesquisadores alegam antagonismo entre o $\mathrm{P}$ e o $\mathrm{Zn}$, em função do aumento da concentração do primeiro, enquanto outros constataram efeito positivo do aumento de $\mathrm{P}$ no teor de Zn e, em alguns casos, verificou-se ausência de resposta (Vieira, 1986; Andrade et al., 2004; Salum et al.,2008).

No caso do manganês, o padrão de curva foi oposto ao zinco. À medida que se elevou a concentração de fósforo na linha de semeadura, a concentração do micronutriente foi menor nas sementes geradas, com certa similaridade a partir dos tratamentos 3 ao 5 , ou seja, com as doses crescentes de P (Figura 6B).

A concentração de ferro foi maior nas sementes provenientes dos tratamentos que receberam mais fósforo na semeadura (Figura 6C), mostrando efeito benéfico do fósforo para o aumento do teor de $\mathrm{Fe}$ na semen- 


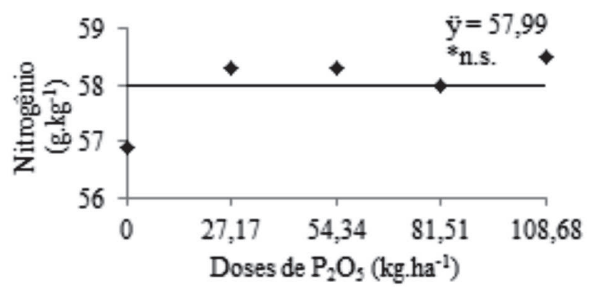

$\mathrm{C}$

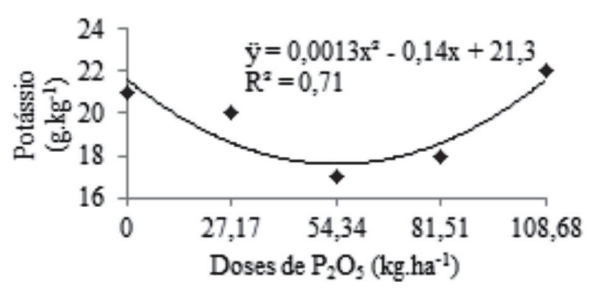

E

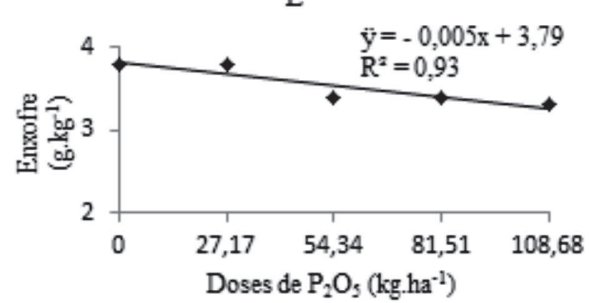

B

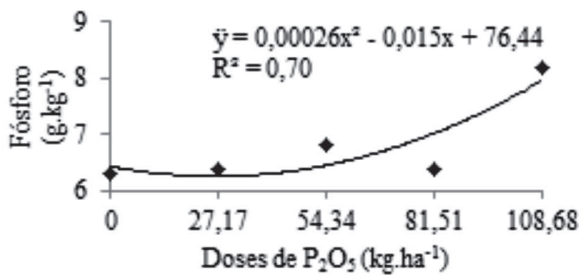

D

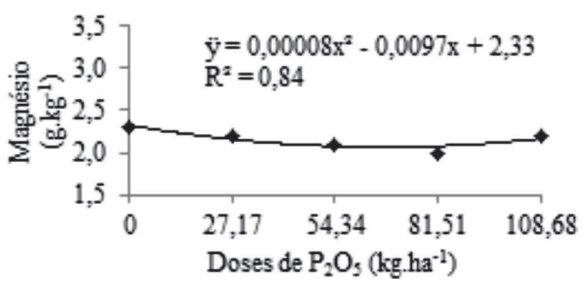

F

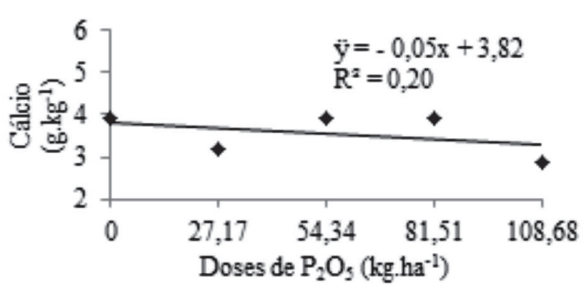

Figura 5. Teores de macronutrientes em sementes de soja, provenientes de plantas cultivadas sob diferentes doses de fósforo na linha de semeadura. *n.s.: não significativo.

A

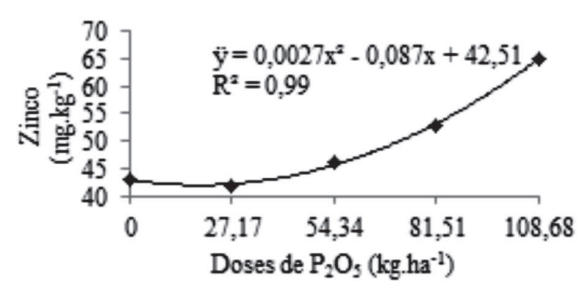

C

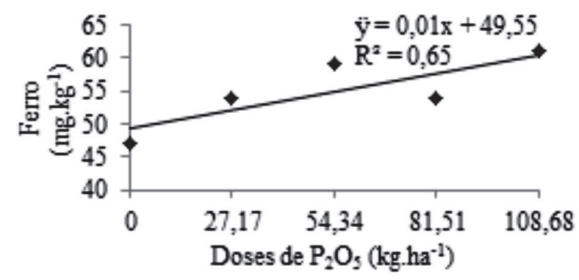

E

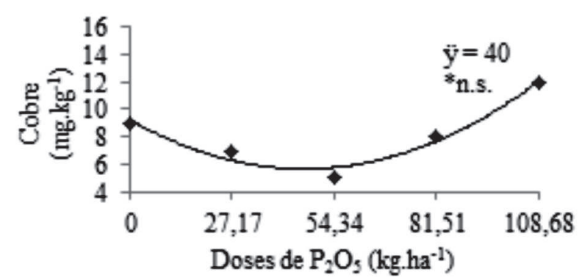

B

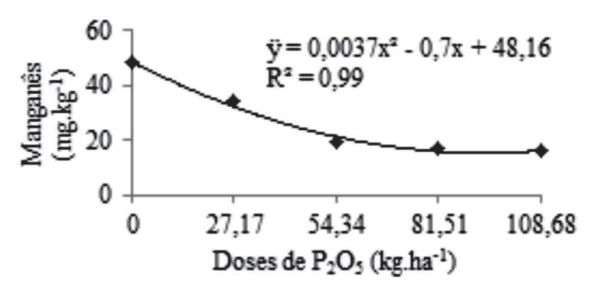

D

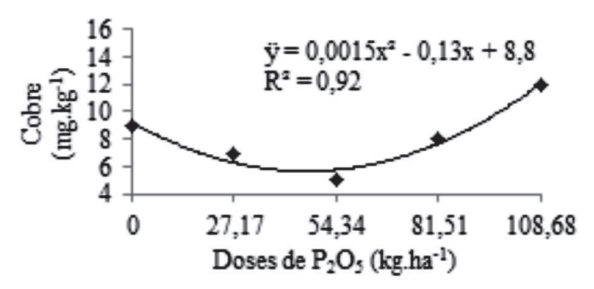

Figura 6. Teores de micronutrientes em sementes de soja, provenientes de plantas cultivadas sob diferentes doses de fósforo na linha de semeadura. 
te. No caso do cobre, o teor deste micronutriente nas sementes passou a se elevar quando as doses de $\mathrm{P}$ na linha de semeadura sobrepuseram ao indicado na análise de solo (Figura 6D). No caso do Boro, este não sofreu influência das diferentes concentrações de P (Figura 6E).

De acordo com Salum et al. (2008), altas concentrações de $\mathrm{P}$ no solo podem afetar a disponibilidade de alguns micronutrientes, como Fe e $\mathrm{Cu}$. Segundo os mesmos pesquisadores, ao estudar a composição química das sementes de feijão do cultivar Carioca Precoce, em relação aos nutrientes $\mathrm{N}, \mathrm{P}, \mathrm{K}, \mathrm{Cu}, \mathrm{Fe}$ e $\mathrm{Mn}$, por causa das diferentes concentrações de $\mathrm{P}$ nas sementes e no solo, constatou-se não haver influência do referido nutriente na alteração da composição das sementes, até mesmo em relação ao próprio fósforo, independentemente do seu teor nas sementes.

Neste estudo, observou-se efeito positivo da maior concentração de $\mathrm{P}$ nas sementes quanto aos micronutrientes $\mathrm{Zn}$ e Fe. Contudo, trabalhos nessa linha precisam ser mais explorados, visando elucidar essas interações, visto que a literatura é escassa nesse quesito, o que se torna relevante para a área de sementes, já que se observaram alterações significativas em alguns macro e micronutrientes em função dos diferentes tratamentos de fósforo na linha de semeadura e, consequentemente, na sua concentração nas próprias sementes geradas.

\section{CONCLUSÕES}

A adubação fosfatada proporciona a produção de sementes com maior vigor, contribui para o aumento da concentração de fósforo, zinco e ferro, principalmente, e reduz a concentração de manganês.

Sementes com maiores concentrações de fósforo em sua constituição contribuem para o aumento de produtividade da soja.

\section{REFERÊNCIAS}

Andrade CA de B, Patroni SMS, Clemente E \& Scapim C (2004) Produtividade e qualidade nutricional de cultivares de feijão em diferentes adubações. Ciência e Agrotecnologia, 28:1077-1086.

Brasil (2009) Regras para análise de sementes. In: Ministério da Agricultura, Pecuária e Abastecimento. Secretaria de Defesa Agropecuária. Brasília, MAPA/ACS. 395p.

Cadore PRB (2011) Desempenho de sementes de trigo revestidas com duas fontes de fósforo. Dissertação de Mestrado. Faculdade de Agronomia Eliseu Maciel, Pelotas. 33p.

Carraro IM \& Peske ST (2005) Uso de sementes de soja no estado do Paraná. Revista Brasileira de Sementes, 27:75-80.

Corrêa JC, Mauad M \& Rosolem CA (2004) Phosphorus in soil and soybean growth as affected by phosphate fertilization and cover crop residues. Pesquisa Agropecuária Brasileira, 39:1231-1237.

França-Neto JB, Krzyzanowski FC \& Costa NP da (1998) O Teste de tetrazólio em sementes de soja. Londrina, EMBRAPA-CNPSO. 72p. (Documetos, 116).
Guerra CA, Marchetti ME, Robaina AD, Souza LCF de, Gonçalves MC \& Novelino JO (2006) Qualidade fisiológica de sementes de soja em função da adubação com fósforo, molibdênio e cobalto. Acta Scientiarum, 28:91-97.

Malavolta E (2006) Manual de nutrição de plantas. São Paulo, Ceres. 638p.

Malavolta E (1980) Elementos de nutrição mineral de plantas. São Paulo, Ceres. 251p.

Moterle LM, Santos RF dos, Lucca e Braccini A de, Scapim CA \& Lana M do C (2009) Influência da adubação com fósforo e potássio na emergência das plântulas e produtividade da cultura da soja. Revista Ciência Agronômica, 40:256-265.

Peske FB, Baudet L \& Peske ST (2009) Produtividade de plantas de soja provenientes de sementes tratadas com fósforo. Revista Brasileira de Sementes, 31:95-101.

Rosolem CA \& Tavares CA (2006) Sintomas de deficiência tardia de fósforo em soja. Revista Brasileira de Ciência do Solo, 30:385-389.

Salum JD, Zucareli C, Gazola E \& Nakagawa J (2008) Características químicas e fisiológicas de sementes de feijão em função do teor de fósforo na semente e doses de fósforo no solo. Revista Brasileira de Sementes, 30:140-149.

Silva RJS \& Vahl LC (2002) Resposta do feijoeiro a adubação fosfatada num Neossolo Litolítico Distrófico da região sul do Rio Grande do Sul. Revista Brasileira de Agrociência, 8:129-132.

Trigo LFN, Peske ST, Gastal MF, Vahl LC \& Trigo MFO (1997) Efeito o conteúdo de fósforo na semente de soja sobre o rendimento da planta resultante. Revista Brasileira de Sementes, 19:111-115.

Vieira RF (1986) Influência de teores de fósforo no solo sobre a composição química, qualidade fisiológica e desempenho no campo de feijão (Phaseolus vulgaris L.). Revista Ceres, 33:173-188.

Zucareli C, Prando AM, Ramos Junior EU \& Nakagawa J (2011) Fósforo na produtividade e qualidade de sementes de feijão Carioca Precoce cultivado no período das águas. Revista Ciência Agronômica, 42:3238 .

Zucareli C, Ramos Junior EU, Barreiro AP, Nakagawa J \& Cavariani C (2006) Adubação fosfatada, componentes de produção, produtividade e qualidade fisiológica em sementes de feijão. Revista Brasileira de Sementes, 28:09-15. 